electrostimulation of the distal stumps of the cut lumbar sympathetic chains being affected (1) in a parallel fashion to that observed in case of i.a. DMPP.

These findings support that at least 3 distinct vasomotor mechanisms are involved in the socalled "sympathetic chain", and that DMPP is likely to stimulate the ganglionic structures involved in these mechanisms, although the present study has not localized these structures in the perfused area and we should always be aware of unspecificity of pharmacological tools.

The present results are consistent with a hypothetis that the active reflex dilatation in dog's hindquarters may be mediated by a mechanism sensitive to antihistaminic agents and insensitive to antimuscarinic or adrenergic beta blocking agents (2).

\title{
REFERENCES
}

1) Beck, L. and Sakuma, A. : Pharmacologist 1, 59 (1959) ; 2) Sakuma, A. And Beck, L. : Ibid. 1, 59 (1959)

\section{PULMONARY EDEMA INDUCED BY EPINEPHRINE INFUSION IN RATS}

\author{
TATSURO SHIGEI, AKIRA SAKUMA AND RYOJI HATANO* \\ Department of Pharmacology, Institute for Cardiovascular Diseoses and Department of Pharmacology*, \\ School of Medicine, Takyo Medical and Dental Universily, Bunkyo-ku, Tokyo \\ Received for publication November 25, 1964
}

In order to study the mechanism and to single out the protective measures against acute pulmonary edema, experimental procedure for producing pulmonary edema by epinephrine infusion in rats was examined.

Male albino rats of Wistar strain, weighing 200 to $300 \mathrm{~g}$, were purchased and housed under controlled conditions for at least two weeks. The animal was anesthetized with pentobarbital, 40 to $50 \mathrm{mg} / \mathrm{kg}$, i.p., and fixed on its back. Polyethylene endotracheal tube was attuched, venous cannula for injection was inserted into the femoral vein, and arterial cannula into the femoral artery for recording blood pressure through a high pressure transducer. Heart rate was recorded with a tachograph. Respiratory movement was traced by means of a costabdominal pneumograph connected to a low pressure transducer.

I.-Epinephrine solution, 50 or $100 \mu \mathrm{g} / \mathrm{ml}, \mathrm{pH} 4$ to 5 , was infused intravenously at a rate of 0.12 $\mathrm{ml} / \mathrm{min}$. When froth or pink liquid appeared in the tracheal tube, the infusion was discontinued and the animal was killed 3 minutes later for examination of the lungs; otherwise, the infusion was terminated after full term of 10 minutes and the animal was killed 5 minutes 1 iter. The lungs were removed after exsanguination via the cut abdominal corta, and the attached tissues were trimmed away for gross observation and weighing. The weight of lungs was expressed as a value, EI (edema index) defined as $10,000 \times$ lung weight divided by body weight.

Epinephrine infusion produced a sustained rise in blood pressure with initial bradycardia and usually depressed respiratory amplitude throughout the period of infusion in animals developi.tig no pulmonary edema. On the other hand, downhill changes superimposed by big fluctuations were

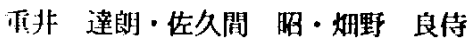

* Present Address : The Ist Department of Surgery, School of Medicine, Tokyo Medical and Dental University, Bunkyo-ku, Tokyo. 

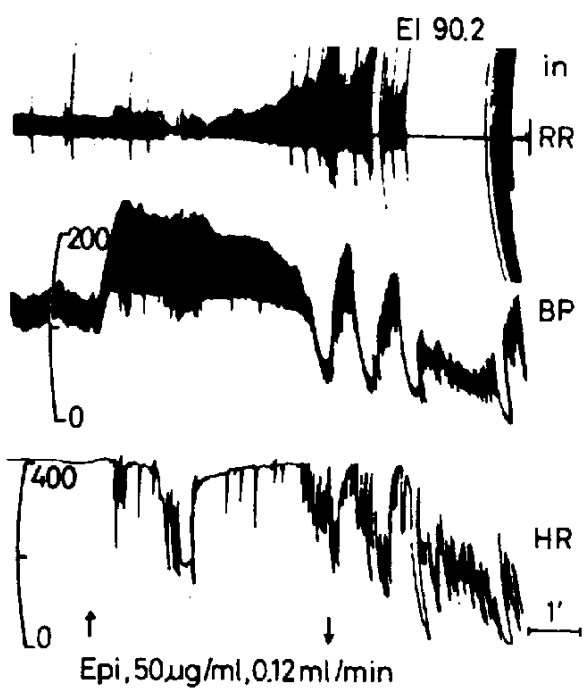

Fig. 1. A typical recording of epinephrine pulmonary edema in rat. Tracings are: respiration ( $R \mathbf{R}$; inspiration, upstroke), blood pressure (BP), heart rate (HR). Epinephrine infusion between arrows.

almost always observed in blood pressure together with irregular respiratory movements in those developing pulmonary edema with froth running (Fig. 1). The lower concentration of epinephrine produced pulmonary edema in 15 rats out of 20 , and the higher 9 out of 9 . The volumes of epinephrine solution required for developing the edema were similar in both concentrations.

The development of pulmonary edema as judged by gross examination is usually associated with i) fluctuations in blood pressure as well as in respiratory recordings, ii) froth or liquid running out of the tracheal tube, and iii) large EI value. In several animals, neither fluctuation in recordings nor froth was noted during 10 minutes' period of epinephrine infusion, but the lungs definitely exhibited edematous outlook and froth came out upon transection of the lower trachea. In animals developing no pulmonary edema EI ranged from 30 to 70 , whereas it was greater

than 50 and often exceeded 100 in the affected rats. The above-mentioned features may serve as good aids in analysing the mechanism of pulmonary edema, but nonc of them is likely a reliable quantitative indicator for severity of the edema produced by epinephrine infusion. Analysis of the results suggests that the induction of pulmonary edema is not directly related to the preexisted blood pressure, the blood pressure rise due to epinephrine infusion and body weight of the animals used in the present study.

\title{
PROTECTIVE EFFEGT OF BROMELAIN AGAINST EPINEPHRINE PULMONARY EDEMA IN RATS
}

\author{
AKIRA SAKUMA, TSUNE NISHIWAKI AND TATSURO SHIGEI \\ Dipartment of Pharmacology, Institute for Cardiovascular Diseases, \\ Tokyo Medical and Dental University, Bunkyo-ku, Takyo \\ Received for publication November 25, 1964
}

Protective effict of bromelain, crude pineapple protease, against pulmonary edema produced by epinephrine infusion was examined in rats. Male albino rats of Wistar strain, 250 to $350 \mathrm{~g}$, were used.

The animal was anesthctized with pentobarbital, intraperitoncally. Endotracheal tube was inselted, respirstory movement, blood pressure and heart rate were recorded. L-Epinephrine solution, $50 \mu \mathrm{g} / \mathrm{ml}$, w:s infused into the femoral vein at a rate of $0.12 \mathrm{ml} / \mathrm{min}$. When froth appeared in the 